\title{
Who Has Room for Error? An Exploration of Voter Accountability and Non-Traditional Candidates*
}

\author{
Akhil Rajan ${ }^{\dagger} \quad$ Christina $\mathrm{Pao}^{\ddagger}$
}

June 2020

\begin{abstract}
It is well established that voters often hold politicians accountable for misbehavior. But are non-traditional (Black, gay, and/or female) candidates held to higher standards? Using a vignette experiment $(\mathrm{N} \approx 4,000)$, we test this question of differential treatment. While we find evidence of outright discrimination, particularly against gay candidates, no evidence of greater penalties for norm violation (corruption or extramarital affairs) emerges. In what we term the "Room for Error Hypothesis," our findings suggest that - though barrier-breaking candidates do not necessarily face stiffer electoral sanctions - they are less able to withstand even diminished penalties given lower baseline support. Further, we hypothesize that gay candidates received lessened penalties from Republicans when charged with norm violation due to "counter-stereotypic" effects: since norm violations send a signal of candidate conservatism to Republicans, this traditionally "negative" candidate quality works to counteract the perception of non-traditional candidates as liberal.
\end{abstract}

*The authors thank Andy Guess, Don Green, Frances Rosenbluth, Peter Aronow, Fredrik Savje, Trevor Incerti, Angele Delevoye, and Cleo O'Brien-Udry for helpful feedback. We especially thank Josh Kalla for his help with this project at all stages.

${ }^{\dagger} \mathrm{BA} / \mathrm{MA}$ Candidate, Yale University

${ }^{\ddagger}$ M.Phil Candidate, University of Oxford 


\section{Introduction}

In 2018, Katie Hill was a rising star in the Democratic Party. A former non-profit executive who ousted a Republican Congressman by an eight point margin in the midterm elections, Hill was widely renown as a prolific fundraiser and, from her perch as Vice Chair of the House Oversight Committee, perhaps the most powerful freshman in Congress. However, that impressive career came crashing down after news reports surfaced that she had been in a relationship with a staffer during her campaign. Shortly after the story broke in late 2019, Congresswoman Hill resigned from public office.

At first glance, Hill's resignation might seem like a victory for the movement to hold powerful politicians accountable for improper behavior. But many critics wondered if Hill had been treated differently from other politicians for two reasons: first, because she is a woman, and second, because the campaign staffer with whom she had an extra-martial affair is a woman as well. Put differently, would Congresswoman Hill have received the same punishment for an affair with a female staffer as a hypothetical Congressman Hill?

Some anecdotal evidence suggests that the answer is no: by 2019, both President Donald Trump and fellow California Congressman Duncan Hunter had been accused of inappropriate relationships with female subordinates. Both had also been accused of rampant political corruption. Yet at the time, both retained their elected positions and won elections even after the charges had come to light. ${ }^{1}$

The political science literature reveals that, to some extent, voters hold their elected officials accountable for misbehavior. The notion of accountability in politics is considered positive, but question remains, is it applied fairly? In an increasingly diverse democracy, it is important to understand whether politicians are held to the same standards. If they are, the case of Congresswoman Hill shows us a new era of political accountability where unequal treatment is yet another barrier for minority politicians. If they are not, Congresswoman Hill might illustrate how voter accountability can reinforce prejudices within the political system that adversely impact minority candidates and legislators. Our study indicates the latter: though voters might penalize candidates of all identities similarly for corruption or affairs, candidates of socially marginalized identities already have lower likelihoods of being elected in the first place, and therefore are more adversely affected by penalties.

Our finding is notable in context of the broader literature. The predominant narrative of past literature - at least with respect to women and non-white candidates - suggests that minority candi-

\footnotetext{
${ }^{1}$ After pleading guilty to misusing campaign funds, Congressman Hunter eventually resigned in 2020, though he won re-election in 2018 despite having been indicted on these same charges.
} 
dates face steeper electoral penalties for the same behavior as their white counterparts. Our results push back: across the board, we find no evidence of excessively harsh penalties for women, gay, and Black candidates and even some evidence of lessened penalties for gay candidates. Instead, the origin of these observed differential consequences for non-traditional candidates is not differential penalties, but rather different starting points. We document how gay candidates (and potentially Black candidates as well) start with lower vote shares among Republican voters, and illustrate how these lowered baselines result in lower levels of support after scandal, compared to more-traditional counterparts. Since returns to vote share are non-linear and subject to thresholds (i.e., the loss in expected utility for a candidate who sees a drop in support from $55 \%$ to $45 \%$ of the two-party vote is greater than from $65 \%$ to $55 \%$ ), candidates with lower baselines receive worse outcomes, even in the face of uniform consequences. In doing so, we upend the primary mechanism established in the literature to explain differential accountability of minority candidates, and provide an alternate explanation for the phenomenon. We find that non-traditional candidates are not treated more harshly after they err; they simply start with less room for error. As a result, our study illustrates a troubling pattern of how even facially neutral accountability measures can entrench existing biases.

\section{Theoretical Basis}

Previous work in voter accountability has shown that, in addition to evaluating candidates based on their prior performance in public office (Fiorina 1978; Kiewiet and Rivers 1984; Ashworth 2012), voters also penalize candidates and officials who have been accused or convicted of scandal. These penalties for participating in behavior that violates political norms often carry as severe sanctions as more objective measures of performance, with some evidence showing average reductions in vote share of $10 \%$ for candidates involved in scandal (Vivyan, Wagner, and Tarlov 2012; Peters and Welch 1980). Typically, past research has disaggregated scandal into "moral" and "financial" types, concluding that both carry significant penalties for candidates' electoral fortunes (Gaskins et al. 2018; Peters and Welch 1978; Carlson 2013).

\section{Voter accountability of minority candidates}

But are these penalties uniform? Past scholars have documented myriad evidence that female legislators are less likely to engage in corruption than their male counterparts (for a review, see Kubbe et al. forthcoming). Perhaps the most simple explanation for this phenomenon is that female 
legislators anticipate higher penalties, and therefore higher risks to corruption (Esarey and SchwindtBayer 2018). As a result, a burgeoning body of literature has examined whether the consequences of scandal differ based on membership in various identities/groups. While there has been much research done in this sphere on women candidates (Eggers, Vivyan, and Wagner 2018; Ionescu 2018; Jones 2014; Funk 1996) and some consideration of Black candidates (Berinsky et al. 2011), this research has not yet extended to gay/lesbian candidates, to the best of our knowledge.

The current literature on differential accountability mechanisms for politicians holds that the source of these greater penalties for women originates in two principal places. First, women are penalized more harshly because they have "farther to fall" (Barnes and Beaulieu 2014; Smith, D. Paul, and R. Paul 2007; Simas and Murdoch 2019). Heightened baseline levels of trustworthiness and lower levels of perceived corruption among hypothetical women candidates - though not necessarily for real-world women candidates - leads to a larger scope for sanctions than for male candidates. Second, some scholars hold that more severe penalties for women may occur as the result of sexism (both benevolent and hostile) that contours expectations for women's behavior (Barnes, Beaulieu, and Saxton 2020).

We also explored an important aspect of this theory as it applies to the nascent literature on voter perceptions of gay/lesbian candidates. With the increase in diversity in many identity-based factors (including open sexual orientation and race) among electoral candidates, there is an increasing need to understand why and how voters treat gay and lesbian candidates. Though Magni and Reynolds (under review) study the electability of $\mathrm{LGT}^{2}$ candidates, little is known about the mechanisms and extent of differential voter accountability for gay and lesbian candidates. We posit that in addition to outright discrimination or biases against gay and lesbian politicians, differential accountability pressures LGT candidates (or candidates of other non-heterosexual, non-cisgender identities) to more strictly comply with social and political norms.

We harbored the same expectation for non-white candidates as well. As Berinsky et al. (2011) observe, scandal can function as an "implicit racial cue when it implicates a black man." They find that then-candidate Barack Obama would be penalized more heavily than then-candidate John Edwards for a similar hypothetical sex scandal. However, the literature does not offer guidance about whether this effect can be universalized. Put differently, it is unclear whether the observed differential consequences for women on issues of financial and moral scandal, and racial minorities on moral scandal emerge

\footnotetext{
${ }^{2}$ Lesbian, gay, and transgender.
} 
from specific instances of stereotypic bias or are part of a broader pattern of indirect penalties for a lack of a demographic norm compliance.

\section{Competing mechanisms for penalization}

At the outset of this project, we offered an additional mechanism that would broaden expectations of differential penalties beyond the lens of individual identity characteristics (e.g., race, gender, sexuality) and suggest applications beyond the realm of scandal: norm compliance. We hypothesized that, as candidates stray further from established political norms, voters sanction them with increasing severity. Therefore, candidates who already fail to conform to voters' demographic expectations are likely to face steeper penalties when they additionally do not conform to their behavioral expectations. As such, voters from traditional backgrounds would be less likely to be held accountable for norm violation, across identities and domains.

However, through our study, we instead found evidence for a less-popular, alternate hypothesis that claims the literature's existing explanation for differential consequences is entirely incorrect: that nontraditional politicians are not, in fact, penalized more harshly. For example, Eggers et al. (2018) find no differences in electoral penalties for women and men who commit the same misbehavior. Though evidence for this alternative hypothesis upends much of the current literature's findings on differential accountability (i.e., particularly those about women candidates, cited above), it might still explain the perception of differential consequences. If minority candidates begin at lower baseline levels of support than their more traditional counterparts, they may possess a lessened ability to withstand even uniform penalties. This idea stems from the fact that political candidates are driven by thresholds: candidates with comfortable pre-scandal electoral margins face less pressure than candidates with tenuous ones.

The ongoing debate and conflict in the literature up to this point likely stems from three principal sources. First, prior studies utilize different samples: two-thirds of studies of political scandals rely on student samples, and few are conducted on nationally representative samples (Sikorski 2018). Second, prior studies utilize different scenarios: many studies ask respondents to select between multiple real-world or hypothetical candidates, which can lead to a variety of biases we attempt to minimize in our own study. Using multiple real-world candidates can introduce candidate-specific confounding factors; for example, using Barack Obama as a stand-in black candidate for a survey experiment might make salient other preexisting opinions about President Obama's policies or time in office. Using multiple hypothetical candidates can make respondents more aware of the candidate's biographical 
manipulation; for example, if a respondent sees one biography of a lesbian female candidate and one biography of a straight male candidate, the respondent might realize that sexuality and gender are salient to the study. And finally, in general, prior studies tend to examine the impacts of race, gender, and sexuality discretely.

In sum, the dominant strand of the literature holds that we should expect to see steeper penalties for at least some minority groups. Our initial expectations held that differential penalties should emerge from factors directly correlated with minority status, and therefore should occur for all minority candidates. However, recent evidence suggests that previous findings of differential voter accountability may no longer obtain. We offer an alternative hypothesis that explains differential consequences even in the face of facially uniform accountability. Therefore, we offer the following study for three principle reasons: first, to arbitrate between these competing hypotheses and mechanisms using a large and nationally representative sample; second, to incorporate queer candidates into the existing literature on candidate penalties; and third, to simultaneously examine intersectional treatment effects across scandal type, race, gender, and sexuality in one study.

\section{Empirical Approach}

To evaluate whether non-traditional (Black, female, and/or gay) candidates face differential penalties for norm transgressions, we implemented an original survey experiment of 4,000 Americans. Our survey respondents were recruited from Lucid from March to April 2020. ${ }^{3}$ All figures and hypotheses presented in this paper come from our pre-registered pre-analysis plan, unless explicitly stated otherwise.

The survey design was a $3 \times 2 \times 2 \times 2$ between-subjects, vignette experiment, wherein we randomized respondents to receive one of three blurbs about a hypothetical election (a control and two treatments). We also randomized whether the candidate in the message was straight or gay, a man or woman, and white or black. By asking respondents to read a statement about a candidate, we hoped to realistically distill information about a candidate that might be available to a voter in a local election. We modeled the control condition after generic candidate bios available on campaign websites, and we modeled the treatments based on typical descriptions of scandals in major news outlets, so as to maximize external validity. Though this does not replicate any one, specific document that would be realistically available

\footnotetext{
${ }^{3}$ Lucid is comparable to Amazon Mechanical Turk (MTurk), and its demographics track well with national benchmarks (Coppock and McClellan 2019).
} 
in an election, it does provide information that would be important and available for a low-information voter in a local race.

In the control message, the respondent merely learns a few generic background facts about a hypothetical candidate, with no reference to any explicit corruption or scandal. The two treatments, one for political corruption and one for an extramarital affair, added a sentence that built upon this control message. Respondents who were in the political corruption treatment group saw an additional sentence explaining that the candidate used state resources to travel with his/her spouse on a foreign trip at the expense of the taxpayer. Respondents who were in the extramarital affair treatment condition saw an additional sentence explaining that the candidate admitted to having an affair with a campaign donor and long time friend. Due to concerns that the candidates would seem too unlikable with the corruption treatments, we drew upon past conjoint experiments to identify which candidate characteristics resonated best with voters (e.g., serving in the Navy) in order to maximize the chances of seeing a measurable and substantively meaningful difference between the control and treatment groups (Bansak et al. 2020). In other words, we tried to create a control candidate who would, according to past literature, be likely to be elected in the first place; if the control candidate were already seen as unlikable, and thus wholly unelectable, we would have been unlikely to see any differentiation between any of our manipulations because of floor effects.

The candidate's identity traits were revealed in the course of the vignette using gendered pronouns and names (e.g., Alexander Foster vs. Alexandra Foster) for both the candidate and their spouse to indicate the candidate's gender and sexuality. Randomly assigning candidate race without triggering social desirability bias or elucidating our manipulation proved more difficult. In order to mirror actual candidate biographies, we used the endorsements of PACs to impute candidate race. The blurb either stated that the candidate was endorsed by a PAC that either supported Black veterans, or one that supported veterans more generally. Importantly, while respondent race and gender were collected as part of the litany of pre-treatment covariates, sexuality was not asked in order to prevent priming.

For individuals who are Democrats/Democratic-leaning (Republicans/Republican-leaning), the candidate in the vignette is said to be running for the Democratic (Republican) primary for municipal office. For true independents (i.e., individuals who did not affiliate with a party and who did not identify as party-leaners when prompted), the candidate in the bio is running for a nonpartisan primary for municipal office. ${ }^{4}$ Each respondent would see a candidate in their own party in order to

\footnotetext{
${ }^{4}$ While nonpartisan primaries are rare at the federal level, they exist in many municipal elections across the country (e.g., Chicago).
} 
Table 1: Text of Treatment Messages

\begin{tabular}{|c|c|c|}
\hline \multicolumn{3}{|c|}{ Treatment Conditions } \\
\hline Control & Political Corruption & Extra-marital Affair \\
\hline $\begin{array}{l}\text { "[Alexander/Alexandra] } \\
\text { Foster is a City Coun- } \\
\text { cil Member running in the } \\
\text { [Democratic/Republican/non- } \\
\text { partisan] primary for Mayor. } \\
\text { Before entering public office, } \\
\text { Foster attended both college } \\
\text { and law school in the state, } \\
\text { and served in the Navy before } \\
\text { becoming a lawyer. During } \\
\text { [his/her] service, [he/she] was } \\
\text { awarded a Silver Star for courage } \\
\text { against an enemy in a war zone. } \\
\text { In this election, [he/she] has } \\
\text { been endorsed by Stars and } \\
\text { Stripes PAC, an organization } \\
\text { dedicated to supporting [vet- } \\
\text { erans/Black veterans]. Foster } \\
\text { has been married to [his/her] } \\
\text { [husband/wife] for five years, } \\
\text { and they have two children." }\end{array}$ & $\begin{array}{l}\text { Control }+ \text { "A breaking } \\
\text { news story that [Alexan- } \\
\text { der/Alexandra] Foster used } \\
\text { government funds to purchase } \\
\text { personal vacations has sent } \\
\text { shockwaves through the race. } \\
\text { Foster admitted to using state } \\
\text { resources to travel with [his/her] } \\
\text { [husband/wife] on an foreign trip } \\
\text { at the expense of the taxpayer." }\end{array}$ & $\begin{array}{l}\text { Control }+ \text { "A breaking } \\
\text { news story that [Alexan- } \\
\text { der/Alexandra] Foster had an } \\
\text { extra-marital affair has sent } \\
\text { shockwaves through the race. } \\
\text { Foster admitted to having an } \\
\text { affair with [Michael/Michelle] } \\
\text { Wallace, a campaign donor and } \\
\text { long-time friend." }\end{array}$ \\
\hline
\end{tabular}

mitigate party's influence in a respondent's favorability of the candidate and likelihood of voting, and to avoid concerns about strategic voting. By minimizing the use of party heuristics, the respondent is instead encouraged to isolate their feelings towards the candidate himself/herself.

A randomization check in Appendix Figure 5 shows that there was demographic balance in each of the eight candidate identity categories (i.e., straight white man, gay white man, straight black man, etc...). Each respondent had only seen one of these messages before being asked the same posttreatment questions about the respondent's favorability, vote choice, perceived electability, perceived trustworthiness, perceived norm compliance, and perceived ideology of the candidate. 


\section{Results}

\section{Do voters differentially penalize non-traditional candidates?}

We initially hypothesized that, overall, scandal (i.e., political corruption and an extramarital affair) would result in a negative penalty for all candidates, but that the penalty would be larger for non-traditional candidates. For our primary analysis, we test this theory using five OLS regression models with robust standard errors. ${ }^{5}$ The dependent variables are respondents' scores of vote choice, favorability, electability, perceived trustworthiness, and perceived norm compliance of the candidates. Vote choice refers to a respondent's likelihood of voting for the candidate. Favorability refers to a feeling thermometer of a candidate's likability. Electability refers to the respondent's belief that the candidate could be elected into office. Trustworthiness refers to how trustworthy the candidate seems based on their vignette. Norm compliance refers to a composite score from 3 questions as to how much the candidates seemed to follow the rules, based on questions from the European Social Survey (Davidov, Schmidt, and Schwartz 2008; Bilsky, Janik, and Schwartz 2010). All scores were normalized to a 0 to 1 scale for ease of comprehension. The models also included additional covariates for the respondent's race, gender, ideology (scored from 1-5, very liberal to very conservative), party, political knowledge (based on Carpini and Keeter 1993), and three dummy variables for support on policies regarding gay marriage, affirmative action, and equal pay. These three dummy variables were included as proxies for baseline support for the gay, black, and female communities. In order to prevent priming, these three policy questions were asked among a battery of questions relating to other salient policy issues (e.g., healthcare, climate change, trade).

\footnotetext{
${ }^{5}$ Since all dependent variables have also been rescaled from 0 to 1 , we also ran ordinal logit models and provided the results in Appendix Figure 6. The findings are substantively equivalent.
} 
Figure 1: Testing for differential penalization of non-traditional candidates

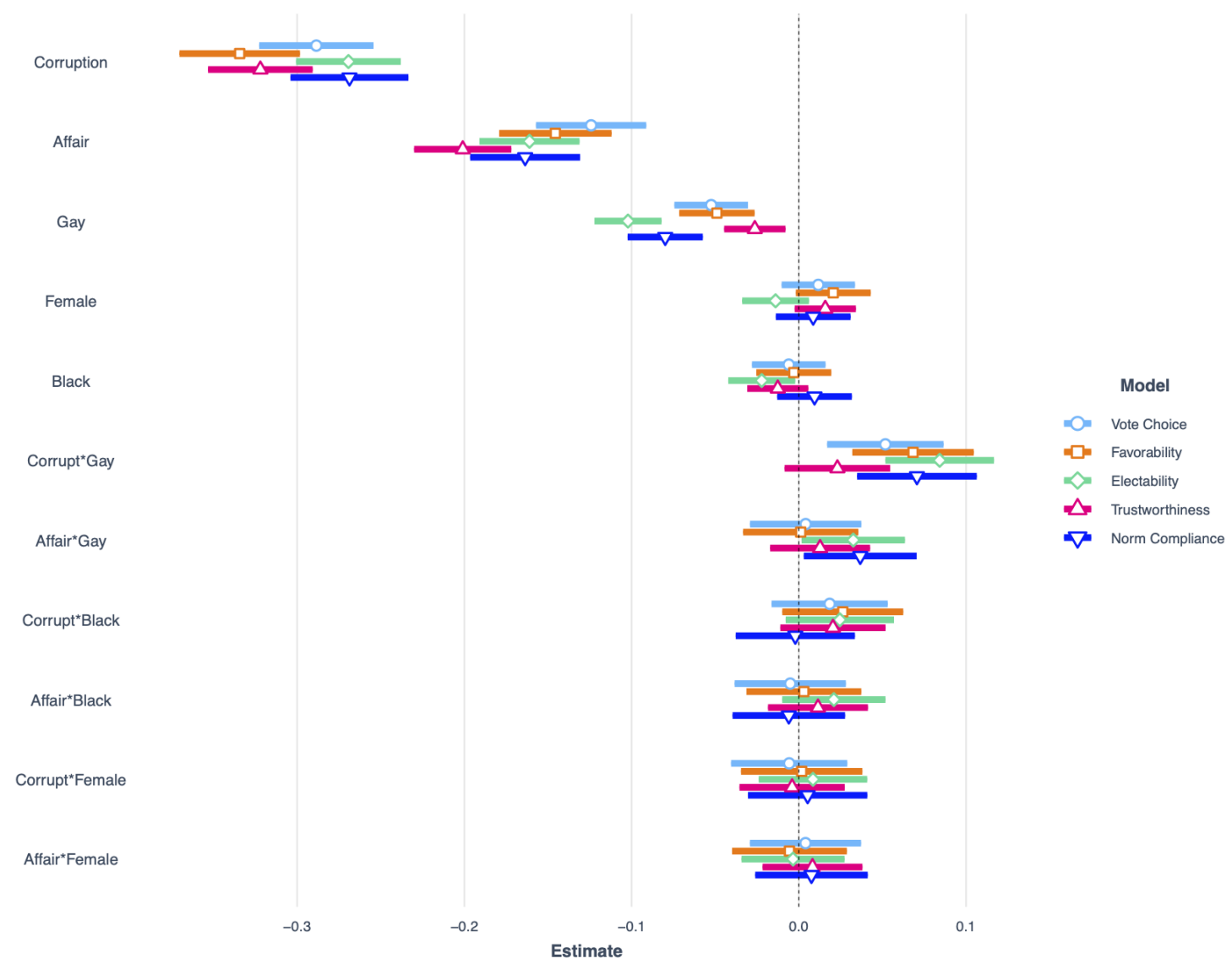

Note: Point estimates represent the coefficients of an OLS model that included all independent variables in the graph and a battery of covariates. The dependent variable is either respondents' vote choice, favorability toward the candidate, perceived electability of the candidate, perceived trustworthiness of the candidate, or perceived norm compliance of the candidate, as indicated in the legend. All dependent variables were re-scaled from zero to one, so point estimates represent proportionate increases on the dependent variable stemming from treatment. Lines represent $95 \%$ confidence intervals with robust standard errors.

In plotting all five of these models together in Figure 1, we find that, as expected, our treatments (corruption and affair) have substantively large and negative effects. Candidates who engaged in political corruption saw their vote shares decline by nearly 30 percentage points, while candidates who engaged in extramarital affairs saw declines of roughly $1 / 3$ magnitude. Though voters may perceive political corruption as more salient to a candidate's ability to perform in office than a more 'personal' matter like an extramarital affair, we believe that this finding itself is one that necessitates further exploration. ${ }^{6}$

\footnotetext{
${ }^{6}$ Some respondents left in optional, open-form comments at the end of the survey that they did not think it was
} 
As predicted, we find significant evidence of discrimination against gay candidates, but contrary to our initial expectations, as a baseline, we find little evidence of outright discrimination for both black candidates and female candidates. ${ }^{7}$ Respondents in the control group were 5.14 percentage points less likely to want to vote for a candidate if he/she were gay. While respondents did believe that, generally speaking, black or female candidates were less likely to be electable, our data shows that black or female candidates were less likely to face outright discrimination in vote share than their gay counterparts.

However, there are several reasons to suspect that our direct measures of candidate prejudice might be conservative. Specifically, our analysis of outright discrimination suffers from two potential shortcomings: a hypothetical bias and a social desirability bias. With respect to the hypothetical bias, stated vote choice in a survey carries zero costs for respondents. As a result, voters do not face the same cross-pressures to violate their norm of equality as they would in real elections (Mendelberg 2001). Similarly, candidate surveys that make demographics salient risk activating responses that align with predominant social attitudes rather than personal opinions (Stoutenborough 2008).

To head off these concerns as best we could in the survey context, and limit the salience of these demographics, we opted not to expose respondents to multiple candidates. However, we still cannot rule out the possibility that our data underestimates the degree of outright prejudice. The lower scores on measures of electability suggest either that respondents harbor prejudice that they are unwilling to personally express, or that they believe that other members of society harbor these prejudices. Certainly, the empirical literature on candidate discrimination is rife with evidence that Black and women candidates face steeper hurdles to attaining elected office (Teele, Kalla, and Rosenbluth 2018; Washington 2020). Since our methodology likely yields conservative estimate, the fact that our study does not find evidence of outright discrimination against women and Black candidates should not be generalized beyond the survey context. However, the fact that we observe significant and substantively meaningful levels of outright discrimination for gay candidates despite these diluting effects suggests that our finding of anti-gay electoral penalties is robust.

Moreover, while our prior assumptions held that non-traditional candidates would be penalized

appropriate to consider the more 'private' matters of the hypothetical candidates in question (i.e., alluding to the information about extramarital affairs). Future research should examine the robustness of this finding that moral scandals are less impactful than financial scandals, and the conditions in which this finding may or may not hold in the real world. For example, are moral scandals that are considered hypocritical (e.g., a conservative anti-gay politician engaging in an affair with a male staffer) penalized more than financial scandals?

${ }^{7}$ Generally speaking, this holds true even when testing for heterogeneous effects by respondent race and gender (see Appendix Figure 7 and 8). These figures show a more clouded picture due to smaller sample sizes, but future work should be done to test whether there is differential in-group/out-group penalization of candidates of different identities. 
more for scandal than their straight, white, male candidates, Figure 1 suggests that there might be only minimal effects. In fact, some evidence suggests non-traditional candidates face slightly lower penalties for norm violation. For instance, gay candidates who had admitted to political corruption face vote share penalties that are 5.2 percentage points higher than their straight counterparts. Although not statistically significant, our point estimates also suggest black candidates who admit to political corruption might also be penalized less severely than their corrupt white counterparts.

\section{More traditional candidates might have 'farther to fall'}

Figure 2: Predicted probabilities for vote choice across treatment and control

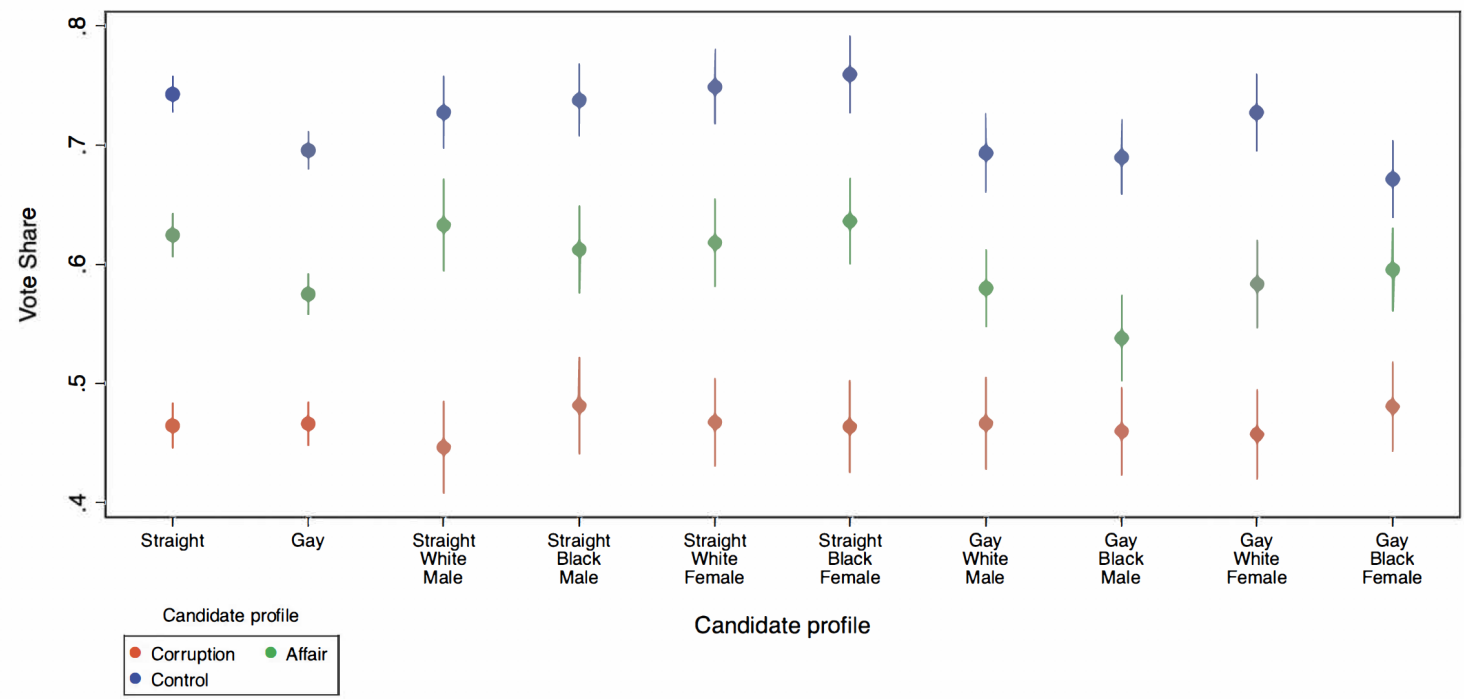

Note: Predicted probabilities represent the mean likelihood that an individual respondent would vote for a candidate in their in-party primary (or in the case of independents, a non-partisan primary). This is mathematically equivalent to the mean vote share they would receive in an election where all respondents voted according to their stated vote choice likelihoods. Lines represent $95 \%$ confidence intervals.

Looking exclusively at the predicted probabilities of each candidate type in Figure 2, we find a potential explanation for this lack of differential penalties. These predicted probabilities were calculated by regressing vote choice on each category of candidate profiles (e.g., white straight man, or black straight woman). Similar to our findings in Figure 1, across the board, norm violation makes the probability of voting for a candidate significantly lower than if the candidate had an affair or no 
stated history of corruption (i.e., the control). Figure 2 also shows that gay candidates across each possible identity arrangement from our survey have lower vote choice baselines than their straight counterparts in both control and the affair treatment.

Interestingly, we do not observe any significant differences between gay and straight candidates in the corruption condition: across the board, voters did not want to vote for candidates who had participated in political corruption. While this might seem equitable at first glance, this finding might suggest evidence for the "farther to fall" hypothesis. If gay candidates have the lowest vote choice baseline in the control group, they seemingly face lower penalties from corruption by virtue of beginning closer to the minimum vote share for a hypothetical in-party candidate. Since the literature holds that gay, black, female candidates are already less likely to be voted in, their vote choice penalty is lower than, for instance, straight white women, who have higher baseline vote share and thus fall farther when they participate in political or personal scandals. We are skeptical that these results arise from floor effects, because our hypothetical candidates still possess a $50 \%$ likelihood of receiving respondents' votes in a primary election, even in the corruption condition.

With seemingly negligible differences in vote share between women and black candidates but significant evidence of discrimination against gay candidates, we next set out to explore what was driving our findings. In our next section, we introduce a new mechanism that explains why gay candidates might specifically face heightened discrimination but lessened penalties from norm violation: respondent partisanship and perceived ideology of the candidate.

\section{Does partisanship affect differential penalization in vote share?}


Figure 3: Testing for differential penalties on non-traditional candidate vote share by Democrats and Republicans

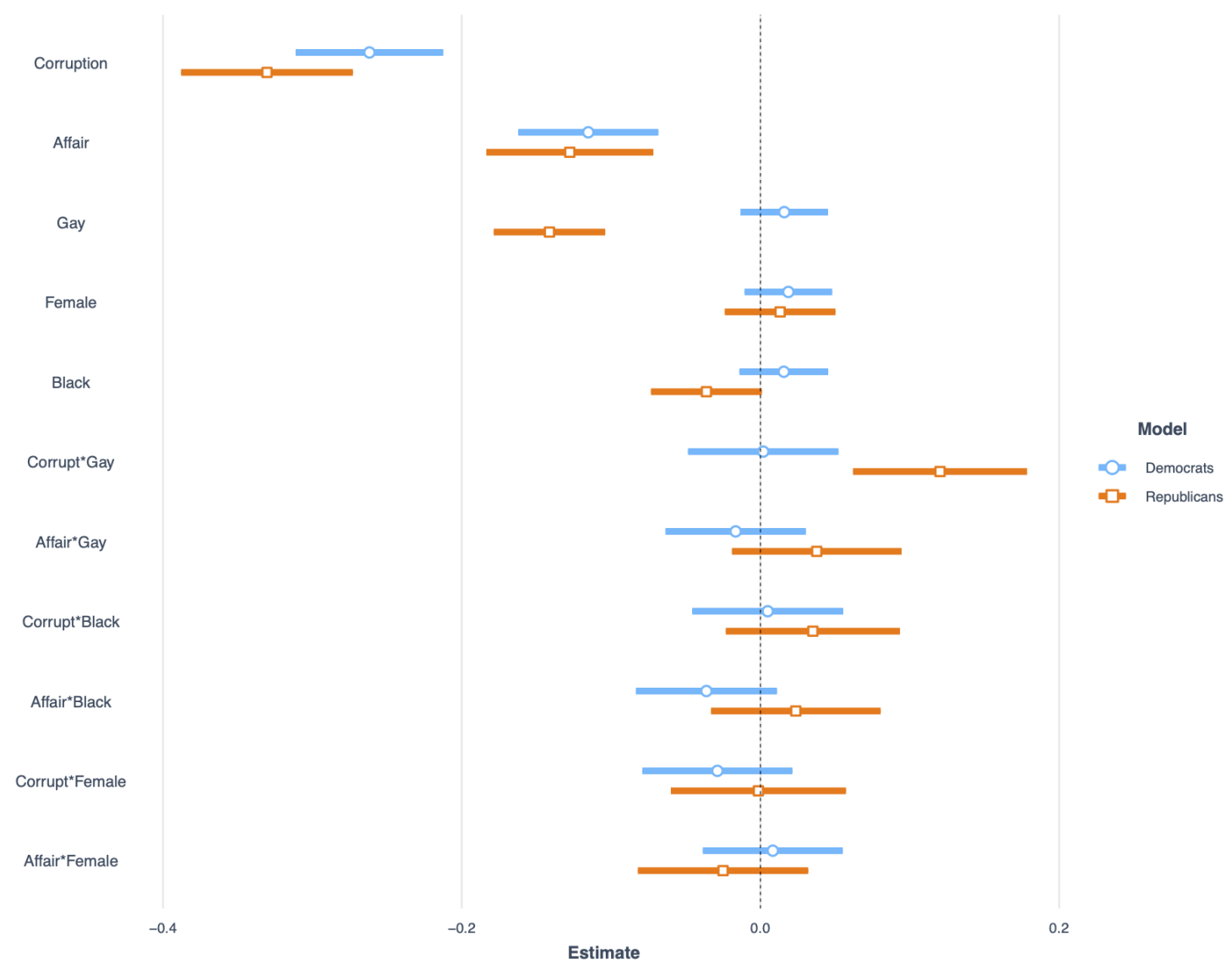

Note: Point estimates represent the coefficients of an OLS model that included all independent variables in the graph and a battery of covariates. Each model was run on the sub-set of respondents who identified with or leaned toward a particular political party. The dependent variable was respondents' vote choice, re-scaled from zero to one. Point estimates therefore represent the change in the likelihood of voting for a candidate on a 0 to 1 scale. Lines represent $95 \%$ confidence intervals with robust standard errors.

We tested whether the same patterns of discrimination and penalization in candidate vote share occurred among both Democrats and Republicans. We were particularly interested in whether party was driving the statistically significant discrimination we saw against gay candidates (Figures 1 and 2) and the significantly lessened penalties for norm violation.

In general, we find that Democrats and Republicans are statistically indistinguishable in their voting preferences for the majority of characteristics in question. However, Republicans and Democrats did differ notably on several metrics. As a baseline, strong evidence emerged of Republican discrimination against Black candidates, and point estimates suggest that Republicans may penalize 
corruption more strongly than Democrats (though this difference was not statistically significant). However, the most striking differences emerged when we examined gay candidates: both our finding of baseline discrimination against gay candidates, and the lessened penalty for politically corrupt gay candidates were driven exclusively by Republicans. While our evidence suggests that Democrats do not penalize gay candidates, a Republican respondent was 13.9 percentage points less likely to vote for a gay candidate, compared to a straight one. Our point estimates indicate that, among Republicans, a gay candidate who remains faithful to their spouse will be penalized more harshly than a straight candidate who admits to an affair. However, though gay candidates have a lower baseline vote share amongst Republicans, Republicans lightened the penalty for gay candidates who also admitted to political corruption. While Democrats were no less or more likely to penalize politically corrupt candidates who were gay (or straight), Republican penalties toward corrupt gay candidates were 12.0 percentage points lower than penalties toward corrupt straight candidates.

\section{Why might gay candidates be penalized less for corruption?}

In addition to the "Farther to Fall" hypothesis, which suggests that all candidates with lower baselines might experience diminished penalties, our research uncovers another potential mechanism underlying the lessened penalties for the gay candidates: scandals offer counter-stereotypic signals of ideology. To understand why Republicans might be more likely to penalize gay candidates without scandal, but less harshly penalize gay candidate with scandal, we tested for the perceived ideology of candidates (with 0 being very liberal and 1 being very conservative). As a baseline, point estimates suggest that both Black and female candidates are seen as more liberal than their white and male counterparts, though neither result is statistically significant. Strikingly, gay candidates are perceived as $13 \%$ more liberal than their otherwise-identical straight counterparts. However, as Figure 4 illustrates, both corruption and affairs increase the perceptions of candidate conservatism. Furthermore, we find that the interaction effect of candidates who are gay and have admitted to a scandal (either corruption or an affair) is positive, meaning that gay candidates with scandal are seen as more conservative than their gay, scandal-less counterparts. ${ }^{8}$

\footnotetext{
${ }^{8}$ This interaction effect of candidates who are gay and have admitted to scandal is also positive when just limiting the sample to Republicans. This is displayed in Appendix Figure 9.
} 
Figure 4: Perceived conservatism of candidates

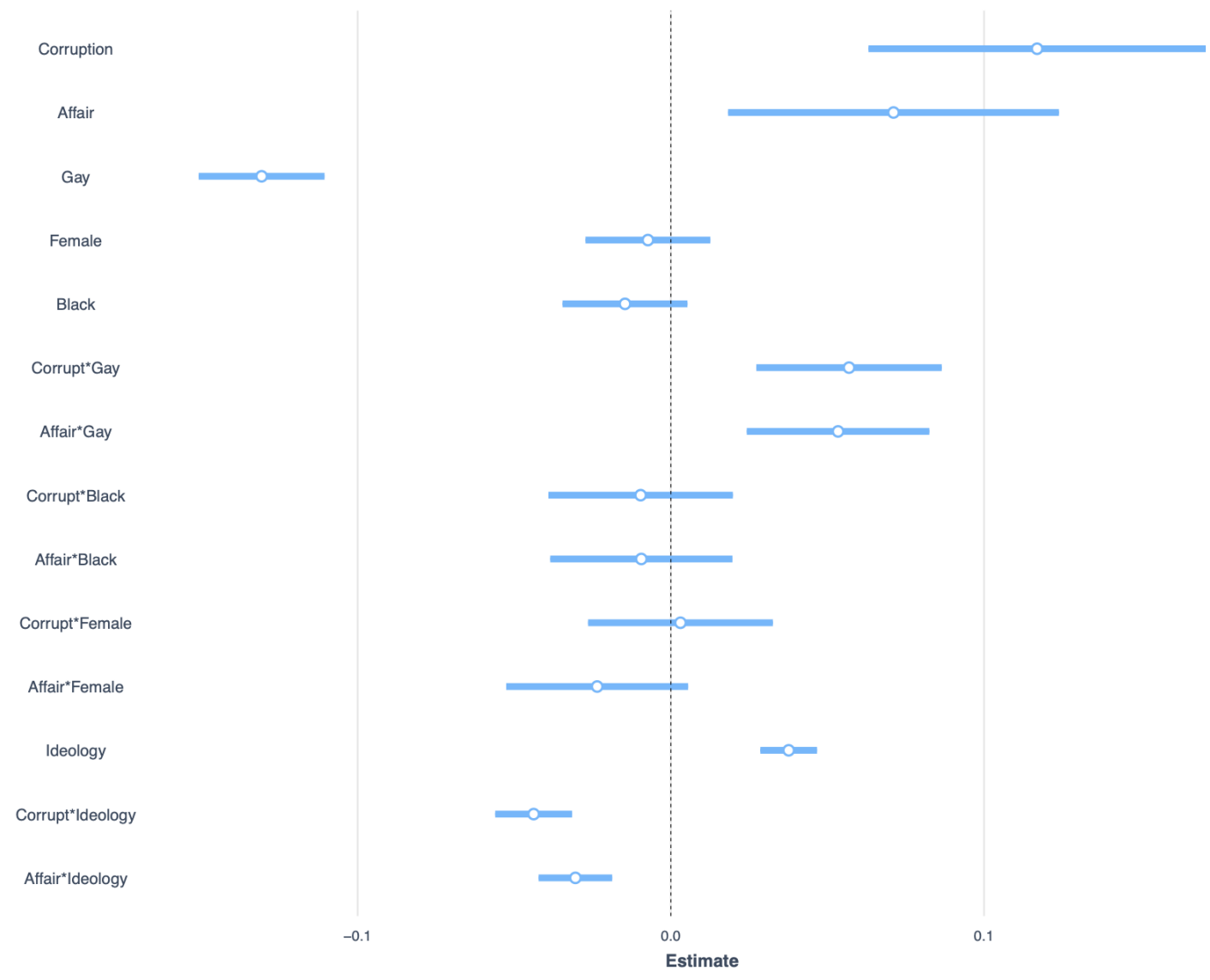

Note: Point estimates represent the coefficients of an OLS model that included all independent variables in the graph and a battery of covariates. The dependent variable was respondents' perceptions of candidate conservatism, re-scaled from zero to one, with zero representing an extreme liberal and one representing extreme conservatism. Point estimates therefore represent the proportionate increase in perceived conservatism stemming from treatment on a 0 to 1 scale. Lines represent $95 \%$ confidence intervals with robust standard errors.

We posit that the perceived liberalness of gay candidates may drive the discrimination observed among Republican respondents. As both our data and a previous study by Magni and Reynolds (forthcoming) suggest, homosexuality is seen as a signal of ideological liberalism. Therefore, conservative respondents might employ statistical discrimination to intuit candidate ideology, and assume that gay candidates will not share their policy viewpoints. However, since respondents appear to view both affairs and corruption as signals of conservatism, the counter-stereotypic effect on ideology of these scandals might lessen their overall penalties for gay candidates. In other words, Republicans who would ordinarily discriminate against gay candidates for their perceived liberalness appear to receive 
a conservative counter-signal from scandal, which in turn moderates penalties for gay candidates.

Our results do not illuminate why respondents view these scandals as signals of ideological conservatism. We offer two potential explanations for future work. The first explanation is contextdependent: with the deluge of scandals involving the Trump Administration, both personal and political, the current media moment likely contains more examples of Republican misbehavior than Democratic. The second is more universal: since conservatives claim the mantle of both fiscal responsibility and moral restraint, corruption and sex scandals strike as more hypocritical, and therefore are more likely to receive media attention. In both cases, media saturation of Republican scandals might cause respondents to associate scandal with conservatism. However, both of these explanations emerged after our experiment, and were therefore not tested in it. We hope that future work disaggregates why both corruption and extramarital affairs are seen as indicators of ideological conservatism.

\section{The "Room for Error" Hypothesis}

While there might be mechanisms - such as a respondent's partisanship or a candidate's perceived ideology - that drive differential penalties between some traditional and non-traditional candidates, on the whole, there is little evidence of heightened penalties for non-traditional candidates. However, we still find troubling evidence of disparate outcomes for non-traditional candidates, driven by unequal baselines.

Our results suggest what we term the "Room for Error" Hypothesis: steeper consequences for norm violation by non-traditional candidates arise from the fact that they begin their political careers with less room for error. While barrier-breaking candidates do not necessarily face stiffer penalties than their more-traditional counterparts, given their lower starting points (particularly in the case of gay candidates), they are less able to withstand these uniform penalties. For instance, Figure 2 illustrates that the baseline probability a respondent will vote for the gay candidate is lower across all demographic conditions; after a fairly uniform decrease for all hypothetical candidates in the affair condition, the probability of voting for a gay candidate who has an affair remains lower than for their straight counterparts.

But because victory in an election requires candidates to overcome certain vote thresholds, these uniform effects will not drive uniform outcomes. For example, a drop from receiving $60 \%$ to $55 \%$ of the two-candidate vote share has different consequences than a drop from $50 \%$ to $45 \%$. The first scenario would transform a comfortable victory into a narrow one. The second scenario would transform a 
narrow victory into a loss. As such, since returns to vote share are non-linear, symmetric penalties have asymmetric consequences that decrease in a candidate's baseline vote share. Our evidence suggests, then, that while traditional candidates can still emerge from some scandals as viable options, their non-traditional counterparts may fall below critical thresholds of viability for the same scandal, even when faced with the same or lesser magnitudes of penalty.

\section{Inferential Challenges}

It is important to note that our study encounters several inferential challenges in examining differential discrimination against candidates. First, as previously noted, there are concerns about social desirability bias, which is when respondents select socially acceptable answers that may not reflect their true preferences. Though we use a between-subjects design, in which respondents see only one message and cannot tell which exact elements we are manipulating, respondents still may wish to look less discriminatory against candidates of marginalized identities. That said, we might expect to see larger effect sizes if that were the case; our estimates for gay discrimination, for instance, might be conservative. On the other hand, experiments with hypothetical candidates might exacerbate treatment effects, compared to real-world settings where manipulations were less salient (McDonald 2019). However, despite these potential biases, some evidence suggests that conjoint and vignette experiments perform 'remarkably well' in uncovering the impacts of demographic characteristics on political outcomes, when analyzed against behavioral data (Hainmueller, Hangartner, and Yamamoto 2015).

Secondly, there have been concerns about whether survey experiments can properly measure the specific impacts of corruption on candidate vote share (Incerti 2020). However, while the effect size of corruption on vote share might be smaller in actuality than would be seen in a survey experiment, much of our study is concerned not with the exact magnitude of the effect size, but with its interaction with other various identity factors. We have no reason to believe that the effect of this hypothetical bias should vary substantially between identities. Moreover, since the sample of real-world non-traditional candidates in each of the treatment conditions we study is both too low for observational study and subject to confounding differences among the types of candidates who run from each identity group, ${ }^{9}$ we believe our survey experiment still sheds important light on the important question of how identity affects voter accountability.

\footnotetext{
${ }^{9}$ For example, Anzia and Berry (2011) find that sex-based selection leads to women politicians that are typically more qualified and effective than their male counter parts.
} 
Finally, we offer a note of caution about interpreting our findings. In both of our treatments, manipulating gender did not change the substance of the information conveyed to respondents. Aside from names and pronouns, the text describing the hypothetical candidate's misconduct remained uniform. We elected to do this in order to isolate the direct effect of gender on voter accountability. But if gender indirectly affects voter accountability through the prism of media (or other personal characteristics, such as appearance), our experiment would not have captured this effect. For example, Uscinski and Goren (2011) and Meeks (2013) document how gender influenced the tone of coverage of Hillary Clinton. This idea suggests that, in addition to any direct bias on the part of the voter as studied in this paper, some degree of bias in accountability could originate in the way misbehavior is framed by the media or other external sources. We leave this question for further observational research.

\section{Conclusion}

At first blush, our results might project optimism for non-traditional candidates. We find no evidence of additional negative penalties for Black, female or gay candidates who partake in the same behavior as their more traditional counterparts. In fact, some of our evidence suggests that gay candidates receive less extreme penalties than their straight counterparts. However, a deeper dive shows that non-traditional candidates face differential consequences from even uniform penalties. We find that voters express outright discrimination toward gay candidates, which in turn lowers their baseline vote shares. Even characteristics proved in the literature to be most respected and driving vote share for candidates (such as being a veteran and having children) are not enough to drive up support for non-traditional candidates relative to white males. Since elections fundamentally revolve around vote thresholds, this means that non-traditional candidates start their campaigns closer to the critical win/loss threshold; subsequently, nontraditional candidates are more likely to lose elections due to scandals. These politicians, then, have less 'room for error,' and suffer disproportionate electoral consequences from even the same or slightly lesser penalties.

We also explore why penalties for misbehavior were lower for gay candidates. Our results suggest that all else equal, gay candidates are perceived as $13 \%$ more liberal than straight candidates. Since both corruption and extra-marital affairs are perceived by voters as signs of ideological conservatism-perhaps because conservative attract more media attention than liberal scandals due to 
perceived hypocrisy or a presidential spotlight - they send a counter-stereotypic signal to voters, and in turn moderate perceptions of gay candidates' ideologies. Since existing work in the literature shows that perceived liberalness diminishes support for gay candidates, the conservative signal sent by affairs and corruption may explain the relatively lessened consequences for affairs and corruption for gay politicians.

Our results also highlight several troubling problems for proponents of political accountability and diversity. First, we show clear evidence of voter discrimination against gay candidates and some evidence of discrimination against Black candidates among Republicans. Next, we show that even non-discriminatory applications of voter accountability can have discriminatory consequences. Though voters did not appear to intend for accountability to reinforce biases against non-traditional candidates - in fact, in some cases they opted for lesser consequences - the net impact did belabor differential consequences. Gay candidates who had extra-marital affairs, for example, still displayed lower probabilities of winning public office than straight candidates who partook in similar behavior across the board. Finally, we show that hypothetically non-ideological misbehavior has fairly large impacts on perceptions of a candidate's ideology. As a result, it is unclear whether voters hold politicians accountable directly for their behavior, or, at least in part, by mistakenly treating scandal as a form of ideological proxy. This is an avenue for future research and direct causal testing.

Returning to our initial discussion of Congresswoman Hill, our results suggest that voters would not have penalized her more harshly than if her male or straight colleagues behaved in the same way. But they do suggest that her lower starting levels of support, compared to an otherwise-equivalent straight candidate, may have rendered her politically inviable after her scandal. Thus, while Congresswoman Hill may have faced the same magnitude of penalties, the "Room for Error" hypothesis explains why she was nonetheless forced to resign for behavior that did not halt the political ambitions of her counterparts from more-traditional backgrounds.

\section{References}

Anzia, Sarah F. and Christopher R. Berry (2011). "The Jackie (and Jill) Robinson Effect: Why Do Congresswomen Outperform Congressmen?" In: American Journal of Political Science 55.3. _eprint: https://onlinelibrary.wiley.com/doi/pdf/10.1111/j.1540-5907.2011.00512.x, pp. 478-493. ISSN: 
1540-5907. URL: https://onlinelibrary.wiley.com/doi/abs/10.1111/j.1540-5907. 2011. 00512.x.

Ashworth, Scott (2012). "Electoral Accountability: Recent Theoretical and Empirical Work". In: Annual Review of Political Science 15.1. _eprint: https://doi.org/10.1146/annurev-polisci-031710103823, pp. 183-201. URL: https://doi.org/10.1146/annurev-polisci-031710-103823.

Bansak, Kirk et al. (2020). "Beyond the breaking point? Survey satisficing in conjoint experiments". In: Political Science Research and Methods (). Publisher: Cambridge University Press, pp. 1-19. IsSN: 2049-8470, 2049-8489. URL: https://www. cambridge.org/core/journals/political-scienceresearch-and-methods / article/beyond-the-breaking-point-survey-satisficing-inconjoint-experiments/47EBFC9D8CE2CA88D6C01870192F8956.

Barnes, Tiffany D. and Emily Beaulieu (Sept. 2014). "Gender Stereotypes and Corruption: How Candidates Affect Perceptions of Election Fraud". In: Politics 83 Gender 10.3. Publisher: Cambridge University Press, pp. 365-391. ISSN: 1743-923X, 1743-9248. URL: https://www.cambridge.org/ core/journals/politics-and-gender/article/gender-stereotypes-and-corruption-howcandidates-affect-perceptions-of-election-fraud/7B1A4F40A1BBC4342416C748A7D5589E.

Barnes, Tiffany D., Emily Beaulieu, and Gregory W. Saxton (Jan. 1, 2020). "Sex and corruption: how sexism shapes voters' responses to scandal". In: Politics, Groups, and Identities 8.1. Publisher: Routledge _eprint: https://doi.org/10.1080/21565503.2018.1441725, pp. 103-121. ISSN: 2156-5503. URL: https://doi.org/10.1080/21565503.2018.1441725.

Berinsky, Adam J. et al. (June 1, 2011). "Sex and Race: Are Black Candidates More Likely to be Disadvantaged by Sex Scandals?" In: Political Behavior 33.2, pp. 179-202. ISSN: 1573-6687. URL: https://doi.org/10.1007/s11109-010-9135-8.

Bilsky, Wolfgang, Michael Janik, and Shalom H. Schwartz (July 20, 2010). "The Structural Organization of Human Values-Evidence from Three Rounds of the European Social Survey (ESS):" in: Journal of Cross-Cultural Psychology. Publisher: SAGE PublicationsSage CA: Los Angeles, CA. URL: https://journals. sagepub.com/doi/10.1177/0022022110362757.

Carlson, Matthew (2013). "Campaign Finance Irregularities, Sex Scandals, and the Election". In: Japan Decides 2012: The Japanese General Election. Ed. by Robert Pekkanen, Steven R. Reed, and Ethan Scheiner. London: Palgrave Macmillan UK, pp. 154-169. ISBN: 978-1-137-34612-4. URL: https://doi.org/10.1057/9781137346124_13. 
Carpini, Michael X. Delli and Scott Keeter (1993). "Measuring Political Knowledge: Putting First Things First". In: American Journal of Political Science 37.4. Publisher: [Midwest Political Science Association, Wiley], pp. 1179-1206. ISSN: 0092-5853. URL: https : //www . jstor.org/stable/ 2111549.

Coppock, Alexander and Oliver A. McClellan (Jan. 1, 2019). "Validating the demographic, political, psychological, and experimental results obtained from a new source of online survey respondents". In: Research $\&$ Politics 6.1. Publisher: SAGE Publications Ltd, p. 2053168018822174. ISSN: 20531680. URL: https://doi.org/10.1177/2053168018822174.

Davidov, Eldad, Peter Schmidt, and Shalom H. Schwartz (Jan. 1, 2008). "Bringing Values Back In: The Adequacy of the European Social Survey to Measure Values in 20 Countries". In: Public Opinion Quarterly 72.3. Publisher: Oxford Academic, pp. 420-445. ISSN: 0033-362X. URL: https: //academic. oup.com/poq/article/72/3/420/1837853.

Eggers, Andrew C., Nick Vivyan, and Markus Wagner (Jan. 1, 2018). "Corruption, Accountability, and Gender: Do Female Politicians Face Higher Standards in Public Life?" In: The Journal of Politics 80.1. Publisher: The University of Chicago Press, pp. 321-326. ISSN: 0022-3816. URL: https://www . journals . uchicago.edu/doi/abs/10.1086/694649.

Esarey, Justin and Leslie A. Schwindt-Bayer (July 2018). "Women's Representation, Accountability and Corruption in Democracies". In: British Journal of Political Science 48.3. Publisher: Cambridge University Press, pp. 659-690. ISSN: 0007-1234, 1469-2112. URL: https://www . cambridge. org/core/journals/british-journal-of-political-science/article/womens-representationaccountability-and-corruption-in-democracies/B2E96DDF18343767DC5E08A43A52420B.

Fiorina, Morris P. (1978). "Economic Retrospective Voting in American National Elections: A MicroAnalysis". In: American Journal of Political Science 22.2. Publisher: [Midwest Political Science Association, Wiley], pp. 426-443. ISSN: 0092-5853. URL: https : //www.jstor.org/stable / 2110623.

Funk, Carolyn L. (Mar. 1, 1996). "The impact of scandal on candidate evaluations: An experimental test of the role of candidate traits". In: Political Behavior 18.1, pp. 1-24. ISSN: 1573-6687. URL: https://doi.org/10.1007/BF01498658.

Gaskins, Ben et al. (Mar. 13, 2018). "From the FEC to the Ballot Box: Voter Accountability for Campaign Finance Law Violations:" in: American Politics Research. Publisher: SAGE PublicationsSage CA: Los Angeles, CA. URL: https://journals.sagepub.com/doi/10.1177/1532673X18759641. 
Hainmueller, Jens, Dominik Hangartner, and Teppei Yamamoto (Feb. 24, 2015). "Validating vignette and conjoint survey experiments against real-world behavior". In: Proceedings of the National Academy of Sciences 112.8. Publisher: National Academy of Sciences Section: Social Sciences, pp. 2395-2400. ISSN: 0027-8424, 1091-6490. URL: https://www.pnas.org/content/112/8/2395.

Incerti, Trevor (June 5, 2020). "Corruption Information and Vote Share: A Meta-Analysis and Lessons for Experimental Design". In: American Political Science Review, pp. 1-14. ISSN: 0003-0554, 15375943. URL: https : / / www . cambridge . org/core/product/identifier/S000305542000012X / type/journal_article.

Ionescu, Luminita (2018). "GENDER INEQUALITY IN POLITICAL DEMOCRACY: ELECTORAL ACCOUNTABILITY, WOMEN'S REPRESENTATION IN GOVERNMENT, AND PERCEIVED CORRUPTION". In: Journal of Research in Gender Studies 8.1. Publisher: Addleton Academic Publishers, pp. 165-171. ISSN: 2164-0262. URL: https : //www . ceeol . com/search/articledetail?id=684924.

Jones, Philip Edward (June 2014). "Does the Descriptive Representation of Gender Influence Accountability for Substantive Representation?" In: Politics $\&$ Gender 10.2. Publisher: Cambridge University Press, pp. 175-199. ISSN: 1743-923X, 1743-9248. URL: https ://www.cambridge.org/core/ journals / politics - and-gender / article / does - the-descriptive-representation- of gender-influence-accountability-for-substantive-representation/2ADED6F88F75F20494FEC307747CD6AF.

Kiewiet, D. Roderick and Douglas Rivers (Dec. 1, 1984). "A retrospective on retrospective voting". In: Political Behavior 6.4, pp. 369-393. ISSN: 1573-6687. URL: https : // doi .org/10 . 1007 / BF00987073.

Kubbe, Ina, Amy Alexander, and Lena Wängnerud (n.d.). "The Effect of Gender on Corruption". In: (), p. 24 .

Magni, Gabriele and Andrew Reynolds (n.d.). "Voter Preferences and the Political Underrepresentation of Minority Groups: Lesbian, Gay, Transgender and HIV+ Candidates in Advanced Democracies". In: (), p. 43.

McDonald, Jared (June 1, 2020). "Avoiding the Hypothetical: Why "Mirror Experiments" are an Essential Part of Survey Research". In: International Journal of Public Opinion Research 32.2. Publisher: Oxford Academic, pp. 266-283. URL: https://academic.oup.com/ijpor/article/ $32 / 2 / 266 / 5540669$. 
Meeks, Lindsey (Jan. 10, 2013). "He Wrote, She Wrote: Journalist Gender, Political Office, and Campaign News". In: Journalism \& Mass Communication Quarterly. Publisher: SAGE PublicationsSage CA: Los Angeles, CA. URL: https : / / journals . sagepub . com/doi / 10 . 1177 / 1077699012468695.

Mendelberg, Tali (Apr. 9, 2001). The Race Card: Campaign Strategy, Implicit Messages, and the Norm of Equality. Google-Books-ID: KNNjghuC46YC. Princeton University Press. 328 pp. ISBN: 978-0-691-07071-1.

Peters, John G. and Susan Welch (1978). "Political Corruption in America: A Search for Definitions and a Theory, or If Political Corruption Is in the Mainstream of American Politics Why Is it Not in the Mainstream of American Politics Research?" In: The American Political Science Review 72.3. Publisher: [American Political Science Association, Cambridge University Press], pp. 974984. ISSN: 0003-0554. URL: https://www.jstor.org/stable/1955115.

- (1980). "The Effects of Charges of Corruption on Voting Behavior in Congressional Elections". In: The American Political Science Review 74.3. Publisher: [American Political Science Association, Cambridge University Press], pp. 697-708. ISSN: 0003-0554. URL: https : //www . jstor .org/ stable/1958151.

Sikorski, Christian von (Aug. 6, 2018). "Political Scandals as a Democratic Challenge- The Aftermath of Political Scandals: A Meta-Analysis". In: International Journal of Communication 12.0. Number: 0, p. 25. ISSN: 1932-8036. URL: https://ijoc.org/index.php/ijoc/article/view/7100.

Simas, Elizabeth N. and Doug Murdoch (July 25, 2019). "II Didn’t Lie, I Misspoke": Voters' Responses to Questionable Campaign Claims". In: Journal of Experimental Political Science. Publisher: Cambridge University Press, pp. 1-14. ISSN: 2052-2630, 2052-2649. URL: https : //www . cambridge .org/core/journals/journal-of-experimental-political-science/article/ i - didnt - lie-i-misspoke - voters - responses - to - questionable - campaign - claims / 29F09434D1B58E412FB7028CDBBB296A.

Smith, Jessi, David Paul, and Rachel Paul (Aug. 14, 2007). "No Place for a Woman: Evidence for Gender Bias in Evaluations of Presidential Candidates". In: Basic and Applied Social Psychology - BASIC APPL SOC PSYCHOL 29, pp. 225-233.

Stoutenborough, James W. (2008). "Demographic Measure". In: Encyclopedia of Survey Research Methods. Thousand Oaks: SAGE Publications, Inc., pp. 186-186. URL: https://sk. sagepub . com/reference/survey/n128.xml. 
Teele, Dawn Langan, Joshua Kalla, and Frances Rosenbluth (Aug. 2018). "The Ties That Double Bind: Social Roles and Women's Underrepresentation in Politics". In: American Political Science Review 112.3. Publisher: Cambridge University Press, pp. 525-541. Issn: 0003-0554, 1537-5943. URL: https : //www . cambridge .org/core/journals/american-political-science-review/ article/ties-that-double-bind-social-roles-and-womens-underrepresentation-inpolitics/617A9986FF59B8934BC300DA21984121.

Uscinski, Joseph E. and Lilly J. Goren (Dec. 1, 2011). "What's in a Name? Coverage of Senator Hillary Clinton during the 2008 Democratic Primary". In: Political Research Quarterly 64.4. Publisher: SAGE Publications Inc, pp. 884-896. ISSN: 1065-9129. URL: https://doi.org/10.1177/ 1065912910382302.

Vivyan, Nick, Markus Wagner, and Jessica Tarlov (Dec. 1, 2012). "Representative misconduct, voter perceptions and accountability: Evidence from the 2009 House of Commons expenses scandal". In: Electoral Studies 31.4, pp. 750-763. ISSN: 0261-3794. URL: http://www.sciencedirect.com/ science/article/pii/S0261379412000960.

Washington, Ebonya (2020). "How Black Candidates Affect Voter Turnout". In: (). URL: https : //core.ac.uk/reader/6894410.

\section{Appendix}

Figure 5: Respondent Demographic Means For Each Candidate Category

\begin{tabular}{|l||c|r|r|r|r|r|}
\hline \multicolumn{1}{|c|}{ Category } & $\mathbf{N}$ & Female & Democrat & Republican & Age & White \\
\hline \hline Straight White Man & 489 & 0.55 & 0.46 & 0.35 & 33.11 & 0.71 \\
\hline Gay White Man & 521 & 0.52 & 0.46 & 0.34 & 31.85 & 0.66 \\
\hline Straight Black Man & 489 & 0.56 & 0.47 & 0.36 & 31.22 & 0.69 \\
\hline \hline Gay Black Man & 514 & 0.55 & 0.46 & 0.35 & 30.59 & 0.72 \\
\hline Straight White Woman & 502 & 0.51 & 0.48 & 0.36 & 31.15 & 0.70 \\
\hline Gay White Woman & 490 & 0.53 & 0.44 & 0.38 & 32.48 & 0.75 \\
\hline Straight Black Woman & 482 & 0.53 & 0.43 & 0.40 & 32.27 & 0.74 \\
\hline Gay Black Woman & 505 & 0.49 & 0.49 & 0.37 & 31.77 & 0.70 \\
\hline \hline
\end{tabular}

Note: All groups had comparable homogeneity, which shows proper randomization. 
Figure 6: Testing for differential penalization of non-traditional candidates using ordinal logit models

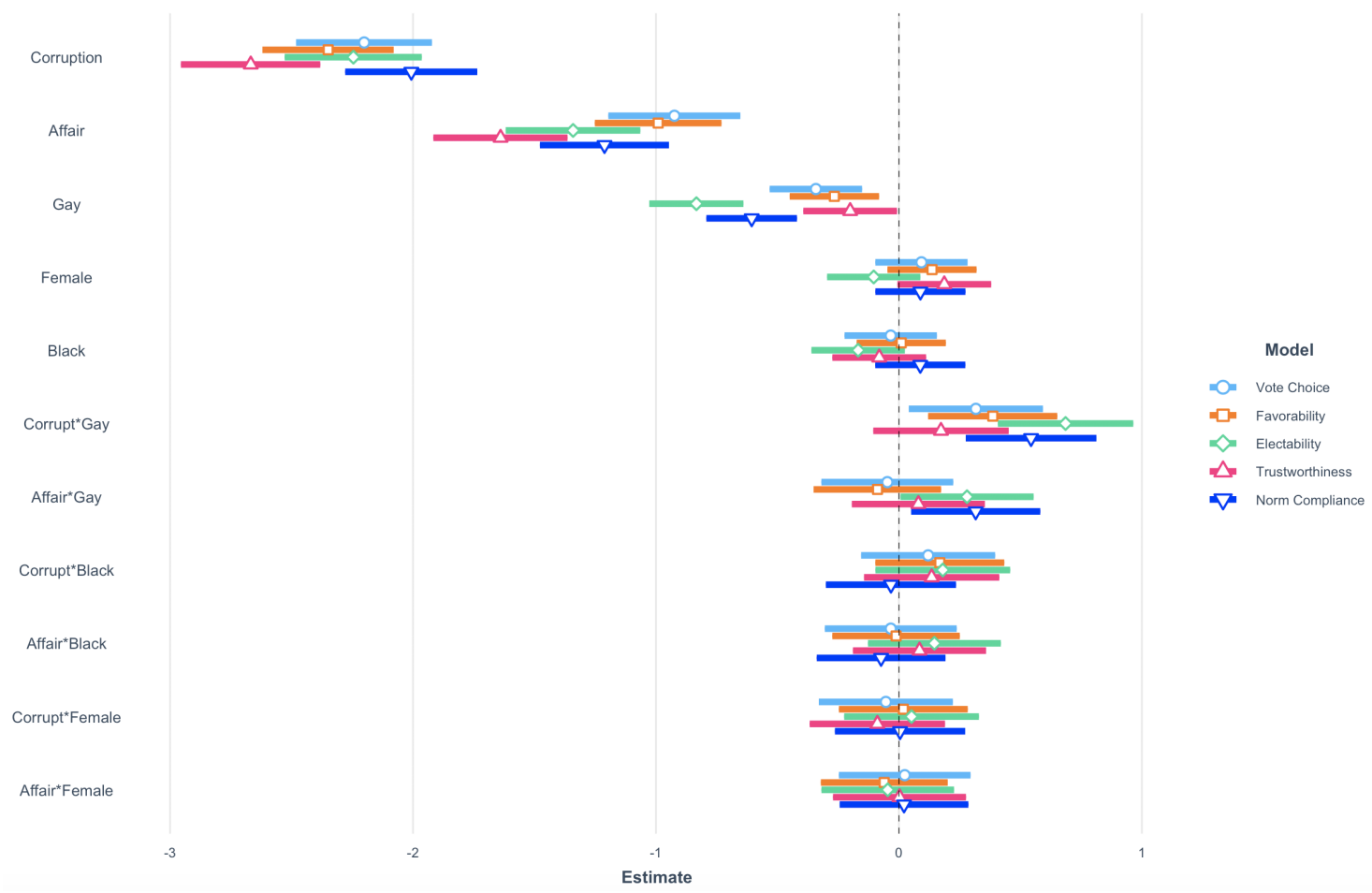

Note: Point estimates represent the results of an ordinal logit model with robust standard errors. The dependent variable is either respondents' vote choice, favorability toward the candidate, perceived electability of the candidate, perceived trustworthiness of the candidate, or perceived norm compliance of the candidate, as indicated in the legend. All dependent variables were re-scaled from zero to one,so point estimates represent proportionate increases on the dependent variable stemming from treatment. Lines represent $95 \%$ confidence intervals. 
Figure 7: Testing for heterogeneous effects by gender

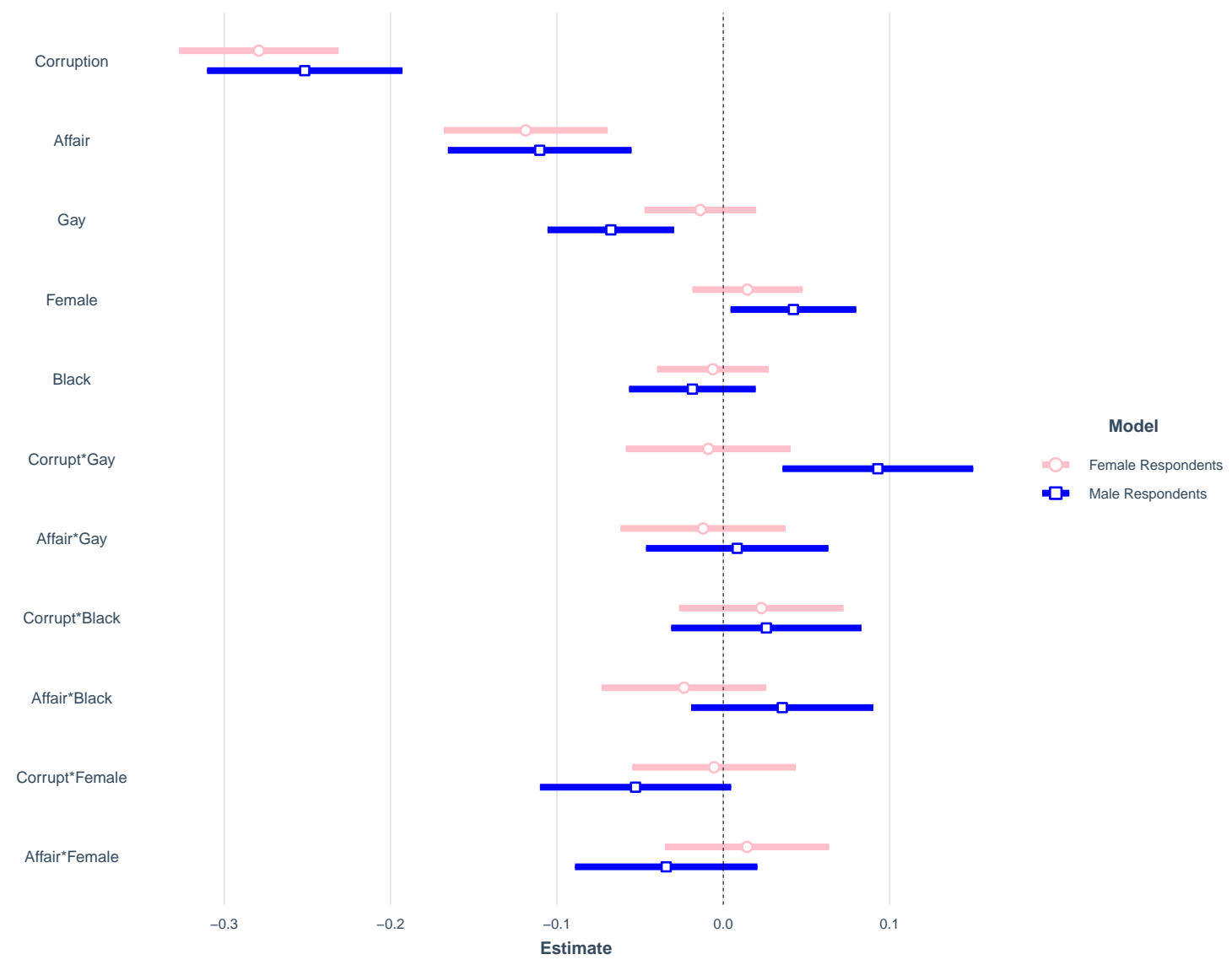

Note: Point estimates represent the coefficients of an OLS model that included all independent variables in the graph and a battery of covariates. Each model was run on the sub-set of respondents who identified as either male or female. The dependent variable was respondents' vote choice, re-scaled from zero to one. Point estimates therefore represent the change in the likelihood of voting for a candidate on a 0 to 1 scale. Lines represent 95\% confidence intervals with robust standard errors. 
Figure 8: Testing for heterogeneous effects by race

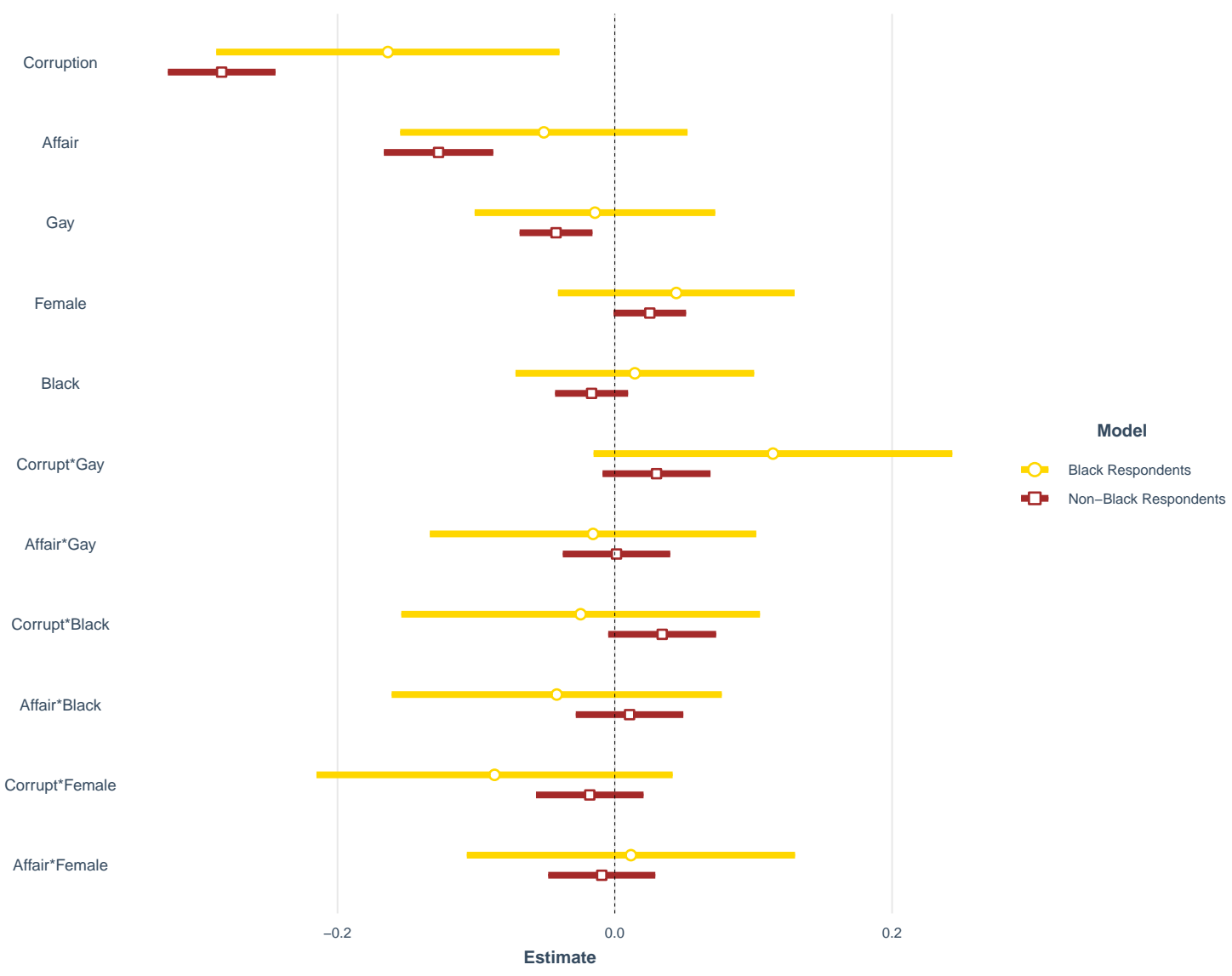

Note: Point estimates represent the coefficients of an OLS model that included all independent variables in the graph and a battery of covariates. Each model was run on the sub-set of respondents who identified as either Black or non-Black. The dependent variable was respondents' vote choice, re-scaled from zero to one. Point estimates therefore represent the change in the likelihood of voting for a candidate on a 0 to 1 scale. Lines represent $95 \%$ confidence intervals with robust standard errors. 
Figure 9: Perceived conservatism of candidates among Republican respondents

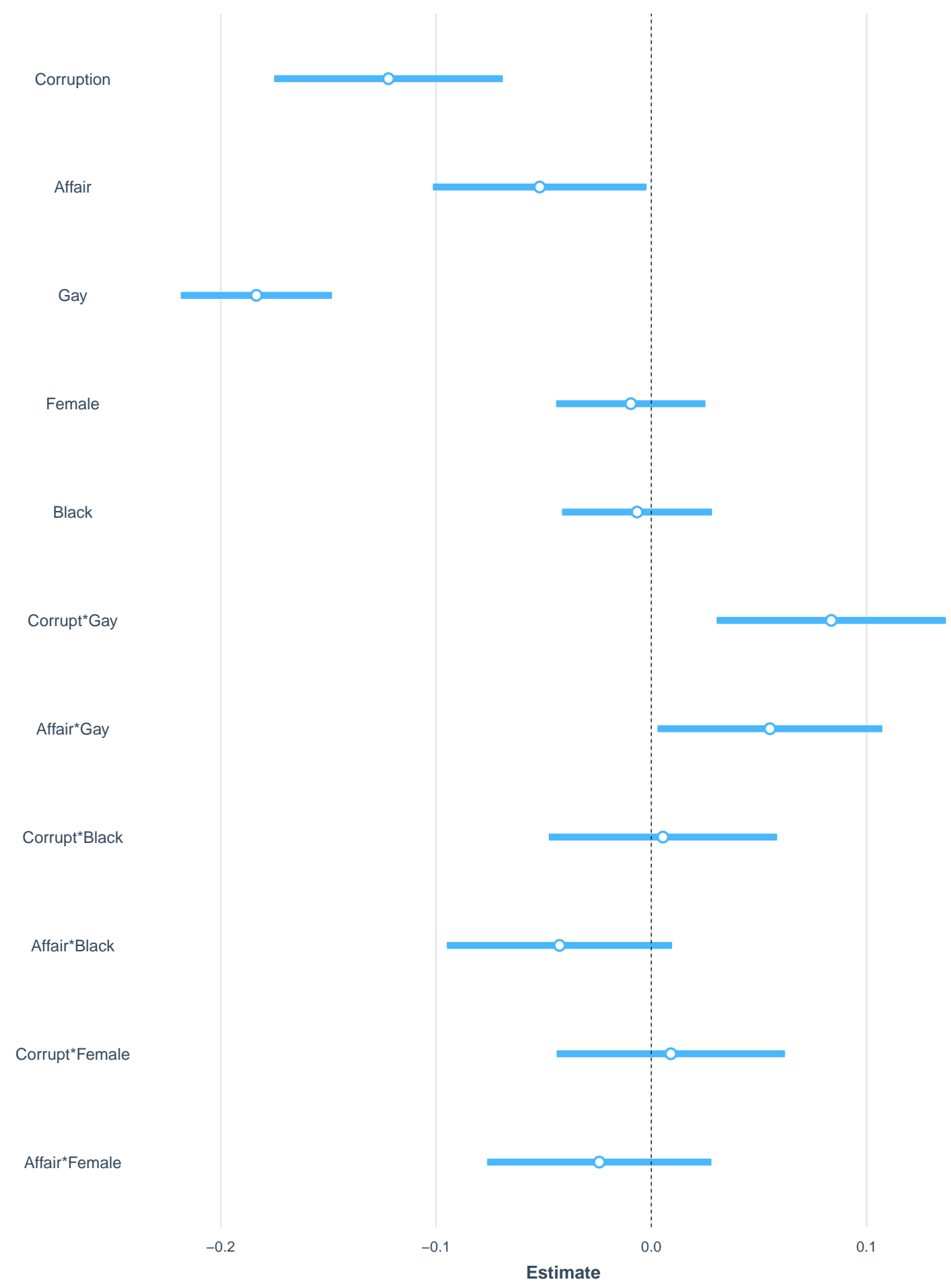

Note: Point estimates represent the coefficients of an OLS model that included all independent variables in the graph and a battery of covariates. The sample was limited to just Republican respondents. The dependent variable was respondents' perceptions of candidate conservatism, re-scaled from zero to one, with zero representing an extreme liberal and one representing extreme conservatism. Point estimates therefore represent the proportionate increase in perceived conservatism stemming from treatment on a 0 to 1 scale. Lines represent 95\% confidence intervals with robust standard errors. 